American Journal of Pharmacology and Toxicology 6 (4): 109-118, 2011

ISSN 1557-4962

(C) 2011 Science Publications

\title{
Vitamin C Alleviates Chronic Chlorpyrifos Induced Alterations in Serum Lipids and Oxidative Parameters in Male Wistar Rats
}

\author{
${ }^{1,2}$ Ambali, S.F., ${ }^{2}$ M. Shittu, ${ }^{2}$ J.O. Ayo, ${ }^{3}$ K.A.N. Esievo and ${ }^{4}$ S.A. Ojo \\ ${ }^{1}$ Department of Veterinary Physiology and Pharmacology, \\ Faculty of Veterinary Medicine, University of Ilorin, Ilorin, Nigeria \\ ${ }^{2}$ Department of Veterinary Physiology and Pharmacology, \\ ${ }^{3}$ Department of Veterinary Pathology and Microbiology, \\ ${ }^{4}$ Department of Veterinary Anatomy, \\ Faculty of Veterinary Medicine, \\ Ahmadu Bello University, Zaria, Nigeria
}

\begin{abstract}
Problem statement: Although the increase incidence of cardiovascular diseases, obesity and diabetes mellitus has been attributed to changing life style, the role of environmental contaminants is currently being given considerable attention. Pesticides, including Organophosphate (OP) insecticides are one of the most pervasive environmental contaminants that are deliberately released into the environment. Chlorpyrifos (CPF), a widely used OP insecticide has been shown to alter lipid profiles, thereby increasing the risk of atherosclerosis. Apart from inhibition of acetyl cholinesterase, oxidative stress is one of the molecular mechanisms involved in CPF-evoked toxicity. Approach: The present study was aimed at evaluating the mitigating effect of vitamin $\mathrm{C}$ on chronic CPF-evoked alteration in lipid profiles in Wistar rats. Twenty young adult male Wistar rats were assigned at random to four groups of five rats each. Groups I, II and III were administered S/oil $\left(2 \mathrm{~mL} \mathrm{~kg}^{-1}\right)$, vitamin C $\left(100 \mathrm{mg} \mathrm{kg}^{-1}\right)$ and $\mathrm{CPF}\left(10.6 \mathrm{mg} \mathrm{kg}^{-1} \sim 1 / 8 \mathrm{th}^{\mathrm{L}} \mathrm{L}_{50}\right)$, respectively while group IV was given vitamin $\mathrm{C}$ $\left(100 \mathrm{mg} \mathrm{kg}^{-1}\right)$ followed by CPF $\left(10.6 \mathrm{mg} \mathrm{kg}^{-1}\right), 30$ min later. The regimens were administered by gavage once daily for 17 weeks. The sera obtained from blood samples were evaluated for the levels of Cholesterol (TC), Triglycerides (TG), High Density Lipoproteins-Cholesterol (HDL-c), Malonaldehyde (MDA) and the activities of superoxide dismutase and catalase. The levels of low Density Lipoprotein-Cholesterol (LDL-c) and Very Low Density Lipoprotein-Cholesterol (VLDL-c) and atherogenic index, were subsequently calculated. Results: The increased levels of TC, LDL-c, MDA and atherogenic index and the decrease in the levels of TG, HDL-c, VLDL-c, SOD and CAT evoked by CPF were mitigated by vitamin C. Conclusion: It is concluded that vitamin $\mathrm{C}$ alleviated the $\mathrm{CPF}$ induced deleterious alterations of lipid profiles, partly due to its antioxidant property.
\end{abstract}

Key words: Chlorpyrifos, lipid profiles, oxidative stress, alleviation, vitamin C, Organophosphate (OP), Triglycerides (TG), Very Low Density Lipoprotein-cholesterol (VLDL-c)

\section{INTRODUCTION}

There has been increasing incidence of cardiovascular diseases, obesity and diabetes mellitus in the last few decades. Although changing life style is one of the risk factors implicated in some of these diseases, the contribution of environmental contaminants cannot be overemphasized. Pesticides are one of the most common contaminants that are deliberately released to the environment to combat the menace of pests that affect the quality and quantity of food resources and serve as vector of insect borne diseases. Organophosphate (OP) insecticides are one of the most widely used as 15 million kilogram were used in agriculture in the United States of America in 2007, representing $36 \%$ of all insecticides used (Grube et al., 2004). Chlorpyrifos, a chlorinated OP insecticide is one of the most widely used (Meeker et al., 2004; California Department of Pesticide Regulation (CDPR), 2010, despite the ban placed on some of its domestic uses by Unites States Environmental Protection Agency in 2000. Although their primary mechanism of systemic toxicity is due to Acetylcholinesterase (AChE) inhibition resulting in cholinergism, it is increasingly

Corresponding Author: Ambali S.F., Department of Veterinary Physiology and Pharmacology, University of Ilorin, Ilorin, Nigeria Tel: +2348037015411 
becoming clear that OP toxicity may involve multiple mechanisms, since toxicity occurs at doses that do not inhibit AChE or long after its restoration (Pope, 1999; Slotkin 2004a; 2004b; Costa, 2006). Oxidative stress is one of the molecular mechanisms implicated in OP toxicity (Gultekin et al., 2001; Goel et al., 2005; Ambali et al., 2007; 2010a; 2010b; Ambali and Ayo, 2011). Lipids are essential for energy homeostasis, reproductive and organ physiology and numerous aspects of cellular biology. They are also linked with many pathological processes, such as obesity, diabetes, heart disease and inflammation. To meet the different demands from a variety of tissues, the body has evolved a sophisticated lipoprotein transport system to deliver cholesterol and fatty acids to the periphery (Lee et al., 2003). Alterations in the concentrations of these lipoproteins affect lipid metabolism with resultant dyslipidemia, a risk factor in atherosclerosis.

The liver, which is responsible for lipid metabolism, is one of the organs that are mostly affected by OP insecticides (Goel et al., 2005; Ambali et al., 2007; 2011; Aly et al., 2010; Tripathi and Srivastav, 2010) due to their role in the detoxification of xenobiotics. Furthermore, the liver is also the site for oxidative desulfuration of $\mathrm{CPF}$ to its more active metabolites, CPF-oxon, a more potent AChE inhibitor. Therefore, the liver, due to these functional roles is vulnerable to injury, which may alter its ability to metabolize lipids. Studies have partly implicated oxidative stress in the molecular mechanism of CPFinduced hepatotoxicity (Goel et al., 2005; Ambali et al., 2007; 2011). A number of studies have shown alterations in lipid profiles following OP exposure (McGill et al., 1981; Quistad et al., 2001; Ibrahim and El-Gamal, 2003; El-Banna et al., 2009; El-Mazoudy et al., 2011). However, studies involving the mitigation of OP induced alterations of lipid profiles by readily available and cheap antioxidant molecules such as vitamin $\mathrm{C}$ become essential in the light of the current environmental and health challenges posed by OP insecticides. The purpose of the present study is to evaluate the mitigating effect of antioxidant vitamin $\mathrm{C}$ on chronic $\mathrm{CPF}$-evoked alterations of lipid profiles in male Wistar rats.

\section{MATERIALS AND METHODS}

Experimental animals: Twenty young adult male Wistar rats $(102 \pm 3$. $2 \mathrm{~g})$ used for this study were obtained from the laboratory animal house of the Department of Veterinary Physiology and Pharmacology, Ahmadu Bello University, Zaria, Nigeria. The animals were housed in metallic cages and were allowed to acclimatize for two weeks in the laboratory prior to the commencement of the experiment. They were fed on standard rat chow and water was provided ad libitum.
Chemical acquisition and preparations: Commercial grade CPF $\left(20 \%\right.$ EC, Termicot $^{\circledR}$, Sabero organics, Gujarat Limited, India), was prepared by reconstituting in soya oil (Grand Cereals and Oil Mills Ltd., Jos, Nigeria) to make $10 \%$ stock solution. Ascorbic acid (100 $\mathrm{mg}^{-1}$; Dol-Med Laboratories Limited, Lagos, Nigeria) was reconstituted in distilled water just prior to its daily administration. All other reagents used in this study were of analytical grade obtained from Sigma Inc., (USA).

Experimental protocol: The rats were weighed and then assigned at random into 4 groups of 5 rats in each group. Group I (S/oil) served as the control group and was given only soya oil ( $2 \mathrm{~mL} \mathrm{~kg}^{-1}$ b.w.) while group II (VC) was given vitamin C (100 mg kg-1 b.w.) Group III (CPF) was administered with reconstituted CPF only (10.6 mg kg ${ }^{-1}$ b.w. 1/8th LD $_{50}$, Ambali (2009) while group IV (VC+CPF) was pretreated with vitamin $\mathrm{C}$ (100 $\mathrm{mg} \mathrm{kg}^{-1}$ b.w.) and then dosed with reconstituted CPF (10.6 mg kg-1 b.w.), 30 min later. The regimens were administered once daily by gavage for a period of 17 weeks. The study was carried out in accordance with the national research council NRC (2011). At the end of the treatment period, the rats were killed by jugular venesection after light ether anesthesia and blood samples were collected into centrifuge tubes, incubated on the shelf for $30 \mathrm{~min}$ and thereafter centrifuged at 800 $\mathrm{xg}$ for $10 \mathrm{~min}$ to obtain the sera samples used to evaluate the lipid profiles and oxidative stress markers.

Evaluation of the effect of treatments on lipid profiles: Serum lipid profiles such as Triglycerides (TG), Total Cholesterol (TC) and High Density Lipoprotein Cholesterol (HDL-c) analyzed. Serum TG concentration was determined by the enzymatic colorimetric method of Bergmeyer (1983). TC was evaluated using the enzymatic colorimetry method of Kayamori et al. (1999), while HDL-c was assessed using the colorimetry method of Finley et al. (1978). Low-Density Cholesterol (LDL-c) and Very Low Density Cholesterol (VLDL-c) were calculated using the formula of Friedewald et al. (1972) thus:

LDL-c $=$ Total cholesterol-HDL Cholesterol- $(0.20 \times$ triglycerides $)$ VLDL-c $=\mathrm{TG} / 5$

Atherogenic Index (AI) was calculated according to Lee and Nieman (1996) thus:

$$
\mathrm{Al}=\frac{\text { Total cholesterol }-\mathrm{HDL}-\mathrm{c}}{\mathrm{HDL}-\mathrm{c}}
$$


Evaluation of the effect of treatments on serum lipoperoxidation: The level of thiobarbituric acid reactive substance, Malonaldehyde (MDA) as an index of lipid peroxidation was evaluated in the sera samples using the method of Draper and Hadley (1990). The principle of the method was based on spectrophotometric measurement of the color developed during the reaction of Thiobarbituric Acid (TBA) with Malonaldehyde (MDA). The MDA concentration in each sample was calculated by the absorbance coefficient of MDA-TBA complex 1.56× $10^{5} \mathrm{~cm}^{-1} \mathrm{M}^{-1}$ and expressed as $\mathrm{nmol} \mathrm{mL}^{-1}$.

Evaluation of the effect of treatments on serum superoxide dismutase activity: Superoxide Dismutase (SOD) activity was evaluated using NWLSSTM superoxide dismutase activity assay kit (Northwest Life Science Specialities, Vancouver, WA 98662) as stated by the manufacturer.

Evaluation of the effect of treatments on serum catalase activity: Catalase (CAT) activity was evaluated using NWLSS ${ }^{\mathrm{TM}}$ catalase activity assay kit (Northwest Life Science Specialities, LLC, Vancouver, WA 98662) as stated by the manufacturer.

Statistical analysis: All data were expressed as mean \pm SEM and then subjected to one-way analysis of variance followed by Tukey's multiple comparism tests. Values of $p<0.05$ were considered significant.

\section{RESULTS}

Serum lipid profiles: The effect of treatments on TC is shown in Fig. 1. There was a significant $(\mathrm{p}<0.05)$ increase serum $\mathrm{TC}$ concentrations in the $\mathrm{VC}$ group relative to the CPF group. Although not significant ( $p>0.05$ ), the TC concentration in the CPF group was relatively higher than that of the C/oil $(9 \%)$ and VC (15\%) groups, respectively.

The serum TG concentration in the CPF group was significantly lower compared to that of S/oil $(p<0.05)$, VC $(p<0.01)$ and $\mathrm{VC}+\mathrm{CPF} \quad(\mathrm{p}<0.05)$ groups, respectively. There was no significant $(p>0.05)$ change in the $\mathrm{TG}$ concentration in the $\mathrm{VC}+\mathrm{CPF}$ group relative to that of S/oil or VC group (Fig. 2).

There was a significant reduction in HDL-c concentration in the CPF group relative to that of S/oil $(\mathrm{p}<0.05)$ and $\mathrm{VC}(\mathrm{p}<0.01)$ groups, respectively. Although not significant ( $>>0.05)$, the HDL-c concentration in the $\mathrm{VC}+\mathrm{CPF}$ group was $23 \%$ higher than that of the CPF group. The HDL-c concentration in the $\mathrm{VC}+\mathrm{CPF}$ group was significantly $(\mathrm{p}<0.05)$ lower than that recorded in the $\mathrm{VC}$ group but no significant $\mathrm{p}>0.05)$ change when compared to that of S/oil group (Fig. 3).

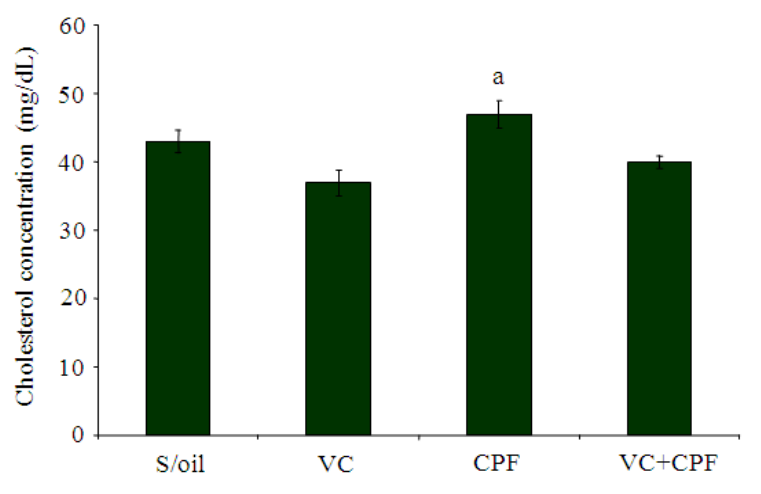

Fig. 1: Effect of Soya oil (S/oil), Vitamin C (VC) and/or Chlorpyrifos (CPF) on serum cholesterol level in male Wistar rats. ${ }^{\mathrm{a}} \mathrm{p}<0.05$ versus $\mathrm{VC}$ group

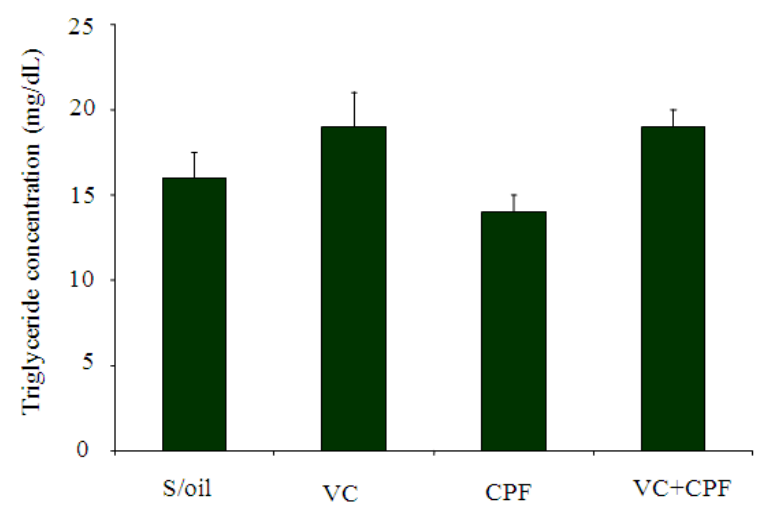

Fig. 2: Effect of Soya oil (S/oil), Vitamin C (VC) and/or Chlorpyrifos (CPF) on serum triglycerides level in male Wistar rats

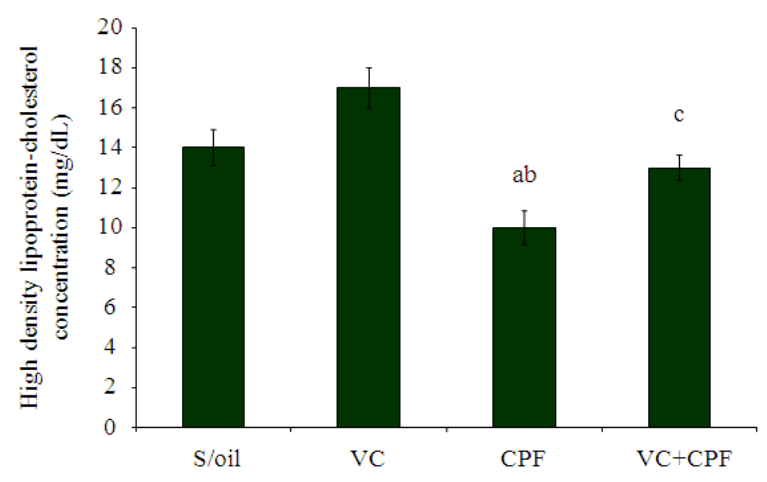

Fig. 3:Effect of Soya oil (S/oil), Vitamin C (VC) and/or Chlorpyrifos (CPF) on serum high density lipoprotein-cholesterol level in male Wistar rats. ${ }^{a} \mathrm{p}<0.05$ versus $\mathrm{S} /$ oil group; ${ }^{b} \mathrm{p}<0.01$ versus $\mathrm{VC}$ group; ${ }^{\mathrm{c}} \mathrm{p}<0.05$ versus $\mathrm{VC}$ group 


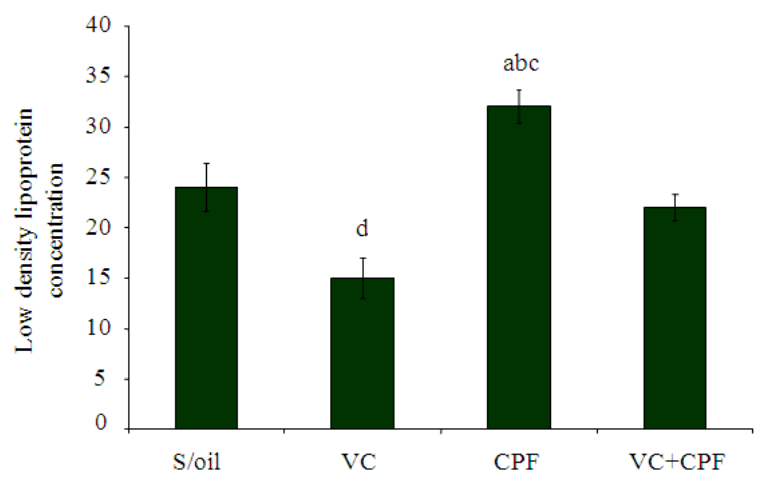

Fig. 4: Effect of Soya oil (S/oil), Vitamin C (VC) and/or Chlorpyrifos (CPF) on serum low density lipoprotein-cholesterol level in male Wistar rats. ${ }^{a b}<0.05$ versus $\mathrm{S} /$ oil and $\mathrm{VC}+\mathrm{CPF}$ groups, respectively; ${ }^{\mathrm{c}} \mathrm{p}<0.01$ versus $\mathrm{VC}$ group; ${ }^{\mathrm{d}} \mathrm{p}<0.05$ versus S/oil group

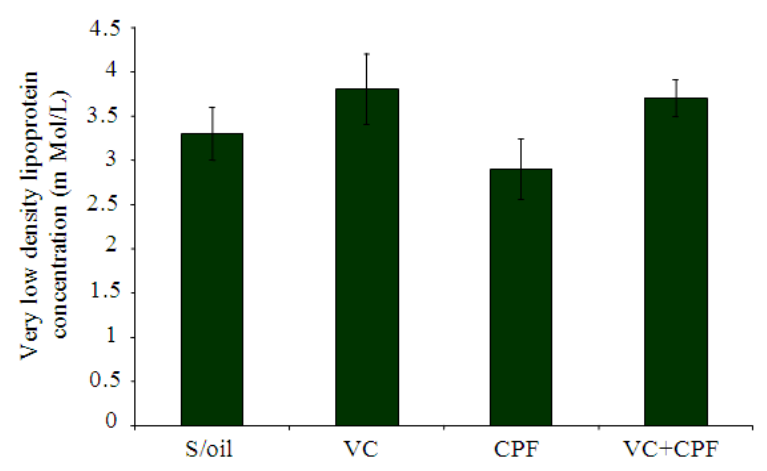

Fig. 5: Effect of Soya oil (S/oil), Vitamin C (VC) and/or Chlorpyrifos (CPF) on serum very low density lipoprotein-cholesterol level in male Wistar rats

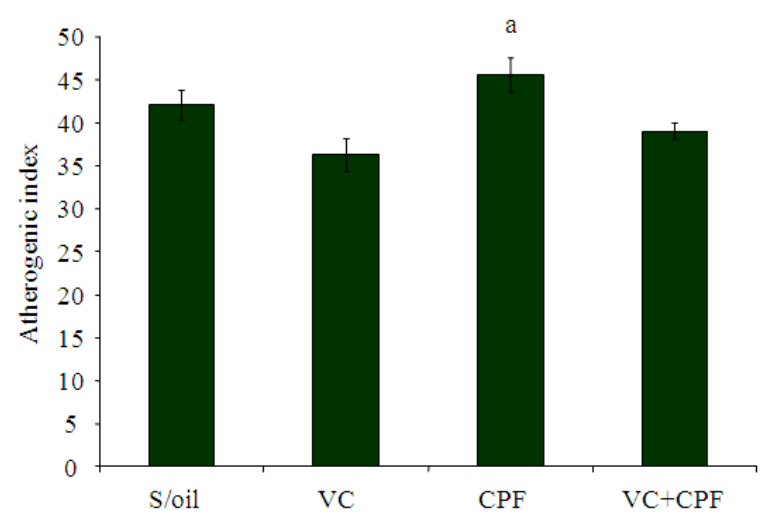

Fig. 6: Effect of Soya oil (S/oil), Vitamin C (VC) and/or Chlorpyrifos (CPF) on atherogenic index in male Wistar rats. ${ }^{a} \mathrm{p}<0.05$ versus VC group

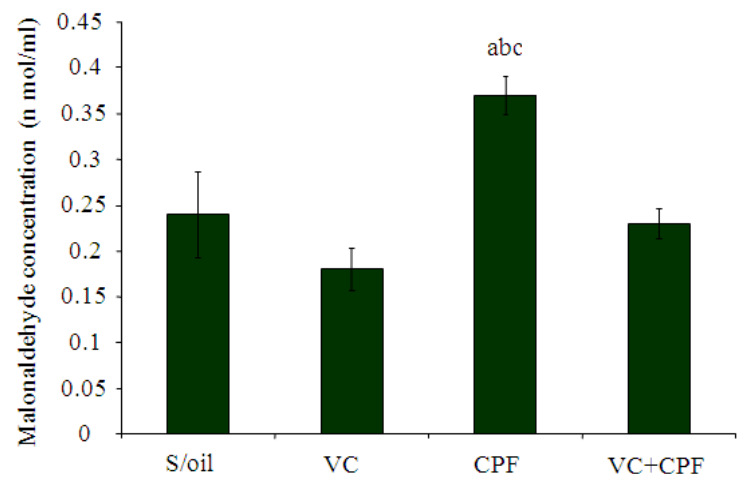

Fig. 7: Effect of Soya oil (S/oil), Vitamin C (VC) and/or Chlorpyrifos (CPF) on serum malonaldehyde concentration in male Wistar rats. ${ }^{a b} \mathrm{p}<0.01$ versus S/oil and $\mathrm{VC}+\mathrm{CPF}$ groups, respectively. ${ }^{c} \mathrm{p}<0.01$ versus VC group

The LDL-c concentration in the CPF group was significantly higher relative to that of S/oil $(p<0.05)$, VC $(p<0.01)$ and $\mathrm{VC}+\mathrm{CPF} \quad(\mathrm{p}<0.05)$ groups, respectively. The LDL-c concentration in the $\mathrm{VC}$ group was significantly $(\mathrm{p}<0.05)$ lower compared to that of S/oil group but no significant $(\mathrm{p}>0.05)$ change when compared to that of $\mathrm{VC}+\mathrm{CPF}$ group (Fig. 4).

There were no significant $(p>0.05)$ changes in the VLDL-c concentrations in between the groups. However, the VLDL-c concentration in the CPF group was relatively lower in the $\mathrm{CPF}$ group relative to that of S/oil (12\%), VC (24\%) and $\mathrm{VC}+\mathrm{CPF}$ (22\%) groups, respectively (Fig. 5).

The AI in CPF group was significantly $(\mathrm{p}<0.05)$ higher compared to that of $\mathrm{VC}$ group. Although not significant ( $p>0.05)$, the AI in the CPF group was relatively higher than that of the S/oil $(8 \%)$ or $\mathrm{VC}+\mathrm{CPF}$ $(14 \%)$ group. There was no significant $(p>0.05)$ change in the $\mathrm{AI}$ in the $\mathrm{VC}+\mathrm{CPF}$ group relative to that recorded in the S/oil or VC group (Fig. 6).

Malonaldehyde concentration: The serum MDA concentration was significantly higher in the CPF group relative to that of $\mathrm{S} / \mathrm{oil}(\mathrm{p}<0.05), \mathrm{VC}(\mathrm{p}<0.01)$ and $\mathrm{VC}+\mathrm{CPF}(\mathrm{p}<0.05)$ groups, respectively. There was no significant $(p>0.05)$ change in the MDA concentration in the $\mathrm{VC}+\mathrm{CPF}$ group relative to that of S/oil or VC group (Fig. 7).

Superoxide dismutase activity: The serum SOD activity in the CPF group was significantly lower relative to that of $\mathrm{C} / \mathrm{oil}(\mathrm{p}<0.05), \mathrm{VC}(\mathrm{p}<0.01)$ and $\mathrm{VC}+\mathrm{CPF}$ $(\mathrm{p}<0.05)$ groups, respectively. There was no significant ( $>0.05$ ) change in the SOD activity in the $\mathrm{VC}+\mathrm{CPF}$ group relative to that of S/oil or VC group (Fig. 8). 


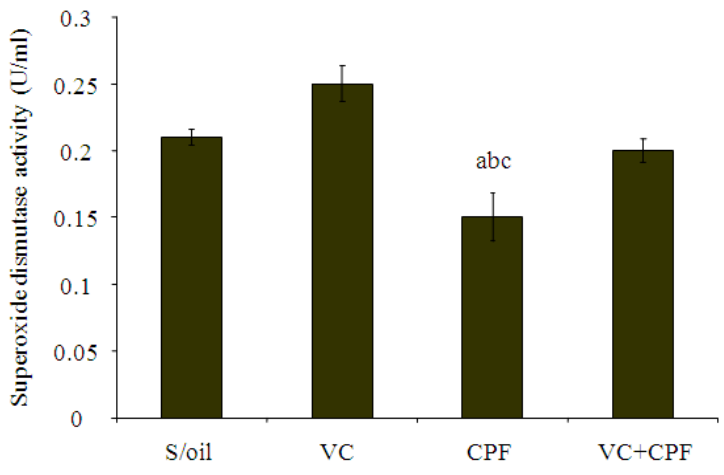

Fig. 8: Effect of Soya oil (S/oil), Vitamin C (VC) and/or Chlorpyrifos (CPF) on serum superoxide dismutase activity in male Wistar rats. ${ }^{a c} \mathrm{p}<0.05$ versus S/oil and $\mathrm{VC}+\mathrm{CPF}$ groups, respectively; ${ }_{\mathrm{p}}^{\mathrm{p}}<0.01$ versus $\mathrm{VC}$ group

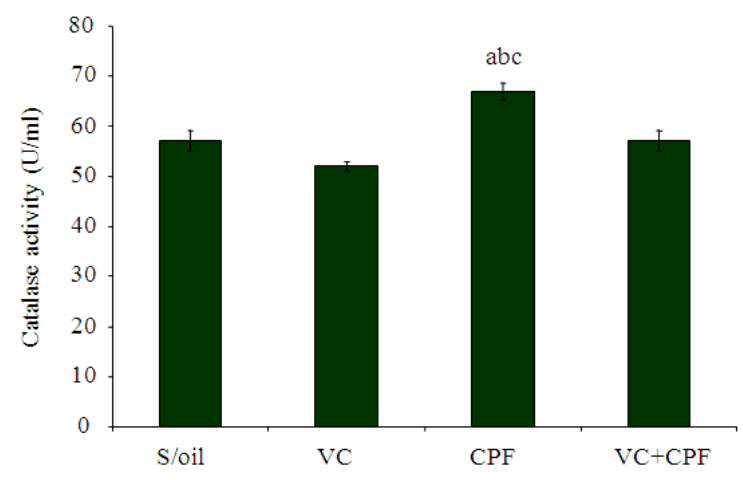

Fig. 9: Effect of soya oil (S/oil), vitamin C (VC) and/or chlorpyrifos (CPF) on serum catalase activity in male Wistar rats. ${ }^{a c} p<0.05$ versus $\mathrm{S} /$ oil and $\mathrm{VC}+\mathrm{CPF}$ groups, respectively; ${ }^{\mathrm{b}} \mathrm{p}<0.01$ versus VC group

Catalase activity: There was a significant decrease in serum CAT activity in the CPF group compared to that of S/oil $(\mathrm{p}<0.05), \mathrm{VC}(\mathrm{p}<0.01)$ and $\mathrm{VC}+\mathrm{CPF}$ $(\mathrm{p}<0.05)$ groups, respectively. The CAT activity in the $\mathrm{VC}+\mathrm{CPF}$ group was not significantly $(\mathrm{p}>0.05)$ different from that of S/oil or VC group (Fig. 9).

\section{DISCUSSION}

The increase serum TC observed in the CPF group in the present study was in accord with the results obtained from earlier studies (Barna-Lloyd et al., 1990; El-Mazoudy et al., 2011) that recorded an increase in TC concentration following repeated CPF exposure. The elevation in serum TC level observed in the CPF group could be due to blockage of liver bile ducts causing reduction or cessation of its secretion to the duodenum (Aldana et al., 2001). Similarly, the ability of the pesticide to interfere with the permeability of the liver cell membrane (Kallender et al., 2005) may have been partly responsible for the high TC. CPF-evoked hepatotoxicity has been previously reported by many workers (Goel et al., 2005; Ambali et al., 2007; 2011). Hypercholestrolemia is a sign of liver damage (Abdou and El-Mazoudy, 2007). Pretreatment with vitamin C was shown in the present study to have apparently reversed the CPF-induced hypercholestrolemia. This may be due the ability of the vitamin to mitigate the hepatic damage evoked by the insecticide, which has been partly attributed to its antioxidant effect (Ambali et al., 2007; 2011a; 2011b). The improved liver function promotes efficient hepatic metabolism of cholesterol.

The present study has also demonstrated a relatively lower TG level in the CPF group and this observation agreed with those obtained in rats by Barna-Lloyd et al. (1990). The relative hypotriglyceridemia in the CPF group may have resulted from liver damage or hypolipoproteinemia (Kaneko et al., 2008; Stojevic et al., 2008) causing reduced interaction of TG with the lipoproteins, especially VLDL. The CPF evoked hypotriglyceridemia may have been due to impaired fatty acids synthesis (Bopanna et al., 1997), enhanced catabolism of VLDL, activation of Lecithin: Cholesterol Acyltransferase (LCAT) and tissue lipases (Khanna et al., 2002), inhibition of acetyl-CoA carboxylase (McCarty, 2001) and production of triglycerides precursors such acetylCoA and glycerol phosphate. Pretreatment with the antioxidant vitamin caused apparent normalization in the TG level. This may be due to the ability of the antioxidant to protect against oxidative damage to the liver by CPF (Ambali et al., 2007), which brings about an improvement in the entire processes that are associated with lipid metabolism.

The study also revealed a lower HDL-c concentration in CPF group, which was in agreement with the findings of El-Mazoudy et al. (2011). Similarly, low-HDL-c has also been reported in rats dosed repeatedly with diazinon (Ibrahim and El-Gamal, 2003). HDL, which is mainly synthesized in the liver and intestinal cells plays an important role in cholesterol efflux from tissues and carries it back to the liver for removal as bile acids (Shakoori et al., 1988). It has been established that the elevated serum or plasma HDLs levels have antiatherogenic effect (McGill et al., 1981), whereas the reduced levels are associated with an increased risk for coronary artery disease (Tietz, 1987). HDLs have been proposed to act in concert with LCAT to remove excess cholesterol from arterial tissue 
and thus prevent atherosclerosis (Glomset, 1979; Fielding and Fielding, 1995). Several lines of evidence suggest that oxidative modification of plasma LDL plays a major role in the pathogenesis of atherosclerosis (Fogelman et al., 1980; Steinberg et al., 1989) and that HDL protects LDL from oxidation (Banka, 1996; Parthasarthy et al., 1990). In addition, the low HDL-c may also be due to CPF induced hepatic damage (Goel et al., 2005; Ambali et al., 2007; 2011) causing impairment of lipoprotein synthesis. The implication of low HDL-c observed in rats chronically exposed to CPF only indicates that prolonged exposure to this insecticide may increase the risk of individuals developing coronary heart disease (Tietz, 1987).

The improvement in HDL-c concentration following vitamin $\mathrm{C}$ pretreatment is a demonstration of the antiatherogenic ability of the antioxidant vitamin. HDL is one of the most important protective factors against arteriosclerosis. This has been attributed to its active participation in the reverse transport of cholesterol (Tomas et al., 2004). In addition, HDL competes with LDL receptor sites on smooth muscle, resulting in partial inhibition of the uptake and degradation of LDL (Attia and Nasr, 2009). The improvement in the HDL-c in the $\mathrm{VC}+\mathrm{CPF}$ group may be partly due to the hepatoprotective effect of the antioxidant vitamin (Ambali et al., 2007; 2011).

The present study has also demonstrated an increase in LDL-c in rats repeatedly exposed to CPF. Similar results were observed by El-Banna et al. (2009) and El-Mazoudy et al. (2011) following CPF exposure. The increased LDL-c may be due to hypercholestrolemia, which suppresses the formation of new LDL receptors thereby decreasing the cellular intake of cholesterol in the form of LDL. The increase in LDL-c recorded in the CPF group, which was accompanied by a low VLDL-c, suggests that CPF exposure promotes the deleterious conversion of some of the VLDL-c to LDL-c. Although hypercholesterolemia is universally accepted as a major risk factor for atherosclerosis, but at any given serum cholesterol concentration, there is variability in the occurrence of cardiovascular events, as it has been shown that the oxidative modification of LDL may be a crucially important step in the development of atherosclerotic plaque (Heinecke, 1997). LDLs transport cholesterol to the arteries where it is retained by arterial proteoglycans, which initiate the formation of plaques. LDL oxidation is thought to be the first step of atherogenesis, followed by foam cell, fatty streakand plaque formation (Nakamura et al., 2008). It has been hypothesized that LDLs can be transported through endothelial tight junctions and/or endothelial transcytosis from the lumen into the intima (Cancel et $a l ., 2007)$, in which blood antioxidants are unlikely to be available and therefore prone to undergo atherogenic oxidative changes (Nakamura et al., 2008). The lack of access to antioxidant by LDL leads to their oxidation. Furthermore the increased MDA concentration and decreased SOD and CAT activities, indicative of oxidative stress in the CPF group further increases the likelyhood of LDL oxidation. Therefore, the increased levels of oxidised LDLs as observed in the present study increased the susceptibility of the rats to atherosclerosis and consequently, heart attack, stroke and peripheral vascular diseases

Pretreatment with vitamin $\mathrm{C}$ was shown in the present study to reduce the serum LDL-c concentration. Therefore, vitamin $\mathrm{C}$ may be able to reduce the susceptibility of individual to $\mathrm{CPF}$ evoked increased susceptibility to atherosclerosis. Although, LDL-c is harmless until oxidized by FR (Teissedre et al., 1996), it is postulated that ingesting antioxidants and minimizing free radical exposure may reduce LDL's contribution to atherosclerosis (Esterbauer et al., 1991; Reaven et al., 1993). Furthermore, the ability of vitamin $\mathrm{C}$ to induce the activity of paraoxonase (Jarvik et al., 2002), a multitask protein that not only hydrolyzes OPs, but also prevents the oxidation of LDLs and HDLs (Chambers, 2008) may enhance protection from atherosclerosis, although oxidation of LDL-c can also occur via nonradical mechanisms such as direct oxidation by lipoxygenase (Carroll, 1989), hypochloric acid and aldehydes (Niki, 2004).

The low VLDL-c in the CPF group may be related to the hypotriglyceridemia recorded, since VLDL is assembled from TG. This finding was in agreement with those of El-Mazoudy et al. (2011). The high conversion of VLDL-c to LDL-c through increased activity of LDL-synthetase complex may have been responsible for its low concentration. Similarly, the increased activity of lipoprotein lipase not only hydrolyzes TGs but also has the effect of reducing VLDL and HDL to smaller fragments (Campbell and Smith, 2000) may have contributed to low VLDL. CPF evoked hepatotoxicity (Goel et al., 2005; Ambali et al., 2007; 2011) may have also contributed to the low VLDL since its synthesis occurs in the liver. VLDL, which is released by the liver, delivers fatty acids to adipocytes for storage and to cardiac and skeletal muscle for energy consumption (Lee et al., 2003). The implication of low VLDL in the CPF group is impairment of fatty acid storage. Pretreatment with vitamin $\mathrm{C}$ was able to increase the VLDL, therefore increasing the propensity of fatty acid storage and metabolism. This may be partly due to mitigation of 
CPF-induced hepatotoxicity by vitamin C (Ambali et al., 2007; Ambali, 2009), which may have improve the lipoprotein synthesis and metabolism. Furthermore, the relatively lowered LDL-c concentration in the vitamin $\mathrm{C}$ pretreated group is a demonstration of a reduction in the rate of conversion of VLDL to LDL.

Atherogenic index, which is used to predict the risk of coronary heart disease, was shown to be significantly higher in the CPF group. This shows that individuals chronically exposed to CPF are predisposed to developing coronary heart disease (Lee and Niemann, 2010). The reduction in atherogenic index by vitamin $\mathrm{C}$ is an indication of the antiatherogenic effect of the vitamin. This may be due to its ability to improve lipid metabolism through its hepatoprotective effect. The antioxidant effect, which decreases the propensity of LDL-coxidation, has contributed to the low atherogenic index. Furthermore, vitamin $\mathrm{C}$ has been shown to increase the activity of Paraoxonase I (PON I) (Jarvik et al., 2002), an arylesterase, synthesized primarily $\mathrm{n}$ the liver and is secreted into the plasma, where it is exclusively bound to High-Density Lipoprotein (HDL) particles containing apoA-I and apoA-j (Kujiraoka et al., 2006), which may have contributed to its antiatherogenic effect. Besides detoxificating OPs, PON1 displays at least two other very important functions including the prevention of unsaturated lipid oxidation and decomposition of lipid peroxidation products of oxidized LDL and HDL in the plasma (Mackness et al., 1998; Shih et al., 1998; Sozmen et al., 2002; Rice et al., 2007). PON1 may also confer protection against damages of vessel wall by antioxidation and destroying oxidative productions.

The increased MDA concentration and increased activities of SOD and CAT in CPF intoxicated rats is a demonstration of increased lipoperoxidation and oxidative stress. MDA is important and most commonly indicator of lipid peroxidation. Therefore, the increased MDA concentration in the CPF group may be due to peroxidation of polyunsaturated fatty acids, leading to degradation of phospholipids and ultimately cellular deterioration (Tappel, 1973). Earlier studies have shown that CPF caused increased lipoperoxidation (Gultekin et al., 2001; Goel et al., 2005; Ambali et al., 2010a and 2010b; El-Mazoudy et al., 2011; Shittu et al., 2012a and 2012b). Cholesterol, cholesterol esters and triglycerides compartments of the lipoprotein fractions can be oxidized by toxic radicals, resulting in the loss of chemical structures and cellular functions (El-Banna et al., 2009). Lipid peroxidation is accepted as a free radical process implicated in the formation of atherosclerosis (Wen et al., 1996). The decreased MDA concentration in the group pretreated with vitamin $\mathrm{C}$ is a demonstration of the antilipoperoxidative property of the vitamin, which was in agreement with previous findings (Aly et al., 2010; Ambali and Ayo, 2011).

The decreased SOD and CAT activities in the CPF group is an indication of oxidative stress, which was in agreement with previous studies (Gultekin et al., 2001; Tuzmen et al., 2007; Ambali and Ayo, 2011; Shittu et al., 2012a; 2012b). The SOD is involved in the dismutation of $\mathrm{O}_{2}{ }^{\mathrm{o}-}$ to $\mathrm{H}_{2} \mathrm{O}_{2}$, while CAT hydrolyzes the $\mathrm{H}_{2} \mathrm{O}_{2}$ to $\mathrm{H}_{2} \mathrm{O}$ and molecular oxygen. The decreased activity of the antioxidant enzymes may have resulted from imbalance in the rate of synthesis to that of utilization. Oxidative stress compromises cellular integrity and function. Furthermore, the increased oxidative stress in the $\mathrm{CPF}$ group may result in the oxidation of LDL-c and HDL-c, thereby increasing the risk of cardiovascular diseases. Vitamin $\mathrm{C}$ has been shown in the present study to increase the activities of SOD and CAT, due to its antioxidant property and thereby decreasing the risk of lipoprotein oxidation, hence atherosclerosis.

\section{CONCLUSION}

The present study has shown that chronic CPF exposure causes oxidative tress and deleteriously alters lipid profiles, thereby increasing the risk of atherosclerosis. Vitamin $\mathrm{C}$ has also been demonstrated in the present study to mitigate the CPF-evoked deleterious alteration of lipid profiles, atherogenic index and oxidative stress, thereby reducing the risk of atherosclerosis.

Conflict of interest: There is no conflict of interest in this study.

\section{REFERENCES}

Abdou, H.M. and R.H. El-Mazoudy, 2007. Myotoxic and hyperlipidemic effects of diazinon in female rats. JMRI, 28: 292-298.

Aldana, L., V. Tsutsumi, A. Craigmill, M.I. Silveira and E.G.D. -Mejia, 2001. $\alpha$-Tocopherol modulates liver toxicity of the pyrethroid cypermethrin. Toxicol. Lett., 125: 107-116. DOI: 10.1016/S03784274(01)00427-1

Aly, N., K. Al-Gendy, F. Mahmoud and A.K. El-Sebae, 2010. Protective effect of vitamin C against chlorpyrifos oxidative stress in male mice. Pestic. Biochem. Physiol., 97: 7-12. DOI: 10.1016/j.pestbp.2009.11.007 
Ambali, S., D. Akanbi, M. Shittu, A. Giwa and O.O. Oladipo et al., 2010a. Chlorpyrifos-induced clinical, hematological and biochemical changes in Swiss albino mice-mitigating effect by coadministration of vitamins $\mathrm{C}$ and E. Life Sci. J., 7: 37-44.

Ambali, S., D. Akanbi, N. Igbokwe, M. Shittu and M. Kawu et al., 2007. Evaluation of subchronic chlorpyrifos poisoning on hematological and serum biochemical changes in mice and protective effect of vitamin C. J. Toxicol. Sci., 32: 111-120. PMID: 17538235

Ambali, S.F. and J.O. Ayo, 2011. Sensorimotor performance deficits induced by chronic chlorpyrifos exposure in Wistar rats: Mitigative effect of vitamin C. Toxicol. Environ. Chem., 93: 1212-1226. DOI: 10.1080/02772248.2011.585991

Ambali, S.F., 2009. Ameliorative effect of vitamins C and $\mathrm{E}$ on neurotoxicological, hematological and biochemical changes induced by chronic chlorpyrifos in Wistar rats. Unpublished PhD Dissertation, Ahmadu Bello University, Zaria.

Ambali, S.F., D.O. Akanbi, O.O. Oladipo, L.S. Yaqub and M.U. Kawu, 2011. Subchronic chlorpyrifos-induced clinical, hematological and biochemical changes in Swiss albino mice: Protective effect of vitamin E. Intl. J. Biol. Med. Res., 2: 497-503.

Ambali, S.F., S.B. Idris, C. Onukak, M. Shittu and J.O. Ayo, 2010b. Ameliorative effects of vitamin $\mathrm{C}$ on short-term sensorimotor and cognitive changes induced by acute chlorpyrifos exposure in Wistar rats. Toxicol. Ind. Health, 26: 547-558. DOI: 10.1177/0748233710373086

Attia, A.M. and H.M. Nasr, 2009. Dimethoate-induced changes in biochemical parameters of experimental rat serum and its neutralization by black seed (Nigella sativa L.) oil. Slovak J. Anim. Sci., 42: 87-94.

Banka, C.L., 1996. High density lipoprotein and lipoprotein oxidation. Curr. Opin. Lipidol., 7: 139-142. PMID: 8818510

Barna-Lloyd, T., J.R. Szabo and N.L. Davis, 1990. Chlorpyrifos-methyl (Reldan R) rat subchronic dietary toxicity and recovery study. Unpublished Report from Dow Chemical Co., TX, USA, submitted to WHO by Dow AgroSciences, Midland, MI, USA.

Bergmeyer, H.U., 1983. Methods of Enzymatic Analysis. 3rd Edn., Vch Pub, New York, ISBN-10: 0895732327.

Bopanna, K.N., J. Kannan, S. Gadgil, E.R. Balaraman and S.P Rathore, 1997. Antidiabetic and antihyperglycaemic effects of neem seed kernel powder on alloxan diabetic rabbits. Indian $\mathrm{J}$. Pharmacol., 29: 162-167.
Campbell, P.N. and A.D. Smith, 2000. Biochemistry Illustrated. 4th Edn., Churchill Livingstone, Edinburgh, ISBN: 044306217X, pp: 218.

Cancel, L.M., A. Fitting and J.M. Tarbell, 2007. In vitro study of LDL transport under pressurized (convective) conditions. Am. J. Physiol. Heart, 293: H126-132. DOI: 10.1152/ajpheart.01188.2006

Carroll, K.K., 1989. Diet, Nutrition and Health. 1st Edn., McGill-Queen's Press, Montreal, ISBN: 0773507418, pp: 347.

Chambers, J.E., 2008. PON1 multitasks to protect health. Proc. N. Y. Acad. Sci., 105: 12639-12640. DOI: 10.1073/pnas.0807062105

Costa, L.G., 2006. Current issues in organophosphate toxicology. Clin. Chim. Acta., 366: 1-13. DOI: 10.1016/j.cca.2005.10.008

Draper, H.H. and M. Hadley, 1990. Malondialdehyde determination as index of lipid peroxidation. Meth. Enzymol., 186: 421-431. PMID: 2233309

El-Banna, S.B., A.M. Attia, M.A. Hafez and S.M. ElKazaz, 2009. Effect of garlic consumption on blood lipid and oxidant-antioxidant parameters in rat males exposed to chlorpyrifos. Slovak J. Anim. Sci., 42: 111-117.

El-Mazoudy, R.H., A.A. Attia and N.S. El-Shenawy, 2011. Protective role of propolis against reproductive toxicity of chlorpyrifos in male rats. Pestic. Biochem. Physiol., 101: 175-181. DOI: 10.1016/j.pestbp.2011.09.003

Esterbauer, H., H. Puhl, M. Dieber-Rotheneder, G. Waeg and H. Rabl, 1991. Effect of antioxidants on oxidative modification of LDL. Ann. Med., 23: 573-581. PMID: 1756027

Fielding, C.J. and P.E. Fielding, 1995. Molecular physiology of reverse cholesterol transport. J. Lipid Res., 36: 211-228. PMID: 7751809

Finley, P.R., R.B. Schilfman, R.J. Williams and D.A. Licht, 1978. Cholesterol in high-density lipoprotein: Use of $\mathrm{Mg} 2+/$ dextran sulfate in its enzymic measurement. Clin. Chem., 24: 931-933. PMID: 207463

Fogelman, A.M., I. Shechter, J. Seager, M. Hokom and J.S. Child et al., 1980. Malondialdehyde alteration of low density lipoproteins leads to cholesteryl ester accumulation in human monocyte-macrophages. Proc. Natl. Acad. Sci. USA., 77: 2214-2218. PMID: 6769124

Friedewald, W.T., R.I. Levy and D.S. Fredrickson, 1972. Estimation of the concentration of lowdensity lipoprotein cholesterol in plasma, without use of the preparative ultracentrifuge. Clin. Chem., 18: 499-502. PMID: 4337382 
Glomset, J.A., 1979. Lecithin: Cholesterol acyltransferase. An exercise in comparative biology. Prog. Biochem. Pharmacol., 15: 41-66. PMID: 224398

Goel, A., V. Danni and D.K. Dhawan, 2005. Protective effects of zinc on lipid peroxidation, antioxidant enzymes and hepatic histoarchitecture in chlorpyrifos-induced toxicity. Chemico-Biol. Interact., 156 : 131-134. $\quad$ DOI: 10.1016/j.cbi.2005.08.004

Grube, A.H., D. Donaldson and T. Kiely, 2004. Pesticides Industry Sales and Usage: 2000 and 2001 Market Estimates. 1st Edn., Biological and Economic Analysis Division, U.S. Environmental Protection Agency, Washington, DC., pp: 33.

Gultekin, F., N. Delibas, S. Yasar and I. Kilinc, 2001. In vivo changes in antioxidant systems and protective role of melatonin and a combination of vitamin $\mathrm{C}$ and vitamin $\mathrm{E}$ on oxidative damage in erythrocytes induced by chlorpyrifos-ethyl in rats. Arch. Toxicol., 75: 88-96. DOI: 10.1007/s002040100219

Heinecke, J.W., 1997. Mechanisms of oxidative damage of low density lipoprotein in human atherosclerosis. Curr. Opin. Lipidol., 8: 268-274. PMID: 9335950

Ibrahim, N.A. and B.A. El-Gamal, 2003. Effect of diazinon, an organophosphate insecticide, on plasma lipid constituents in experimental animals. J. Biochem. Mol. Biol., 36: 499-504. PMID: 14536034

Jarvik, G.P., T.N. Tsai, L.A. McKinstry, R. Wani, V. Brophy and R.J. Richter et al., 2002. Vitamin C and $\mathrm{E}$ intake is associated with increased paraoxonase activity. Arterioscl Thromb. Vasc. Biol., 22: 1329-1333. $\quad$ DOI: 10.1161/01.ATV.0000027101.40323.3A

Kallender, S., A. Ogutcu, M. Uzunhisarcikli, F. Acikgoz and D. Durak et al., 2005. Diazinoninduced hepatotoxicity and protective effect of vitamin $\mathrm{E}$ on some biochemical indices and ultrastructural changes. Toxicology, 211: 197-206. DOI: 10.1016/j.tox.2005.03.007

Kaneko, J.J., J.W. Harvey and M. Bruss, 2008. Clinical Biochemistry of Domestic Animals. 6th Edn., Academic Press, Amsterdam, Boston, ISBN: 9780123704917, pp: 916.

Kayamori, Y., H. Hatsuyama, T. Tsujioka, M. Nasu and Y. Katayama, 1999. Endpoint colorimetric method for assaying total cholesterol in serum with cholesterol dehydrogenase. Clin. Chem., 45: 2158-2163. PMID: 10585348
Khanna, A.K., F. Rizvi and R. Chander, 2002. Lipid lowering activity of Phyllanthus niruri in hyperlipemic rats. J. Ethnopharm., 82: 19-22. DOI: 10.1016/S0378-8741(02)00136-8

Kujiraoka, T., H. Hattori, Y. Miwa, M. Ishihara and T. Ueno et al., 2006. Serum apolipoprotein $\mathrm{j}$ in health, coronary heart disease and type 2 diabetes mellitus. J. Atheroscler. Thromb., 13: 314-322. PMID: 17192696

Lee, C.H., P. Olson and R.M. Evans, 2003. Minireview: Lipid metabolism, metabolic diseases and peroxisome proliferator-activated receptors. Endocrinol., $\quad 144$ : 2201-2207. DOI: 10.1210/en.2003-0288

Lee, R.D. and D.C. Niemann, 2010. Nutritional Assessment. 5th Edn., McGraw-Hill Education, Dubuque, IA., ISBN-10: 0072927313, pp: 580.

Mackness, B., M.I. Mackness, S. Arrol, W. Turkie and P.N. Durrington, 1998. Effect of the human serum paraoxonase 55 and 192 genetic polymorphisms on the protection by high density lipoprotein against low density lipoprotein oxidative modification. FEBS Lett., 423: 57-60. PMID: 9506841

McCarty, M.F., 2001. Inhibition of acetyl-CoA carboxylase by cystamine may mediate the hypotriglyceridemic activity of pantethine. Med. Hypoth., 56: 314-317. DOI: 10.1054/mehy.2000.1155

McGill, H.C. Jr., C.A. McMahan, A.W. Kruski and G.E. Mott, 1981. Relationship of lipoprotein cholesterol concentrations to experimental atherosclerosis in baboons. Arteriosclerosis, 1: 312. PMID: 6945831

Meeker, J.D., 1. Ryan, D.B. Barr, R.F. Herrick and D.H. Bennett et al., 2004. The relationship of urinary metabolites of carbaryl/naphthalene and chlorpyrifos with human semen quality. Environ. Health Perspect., 112: 1665-1670. DOI: 10.1289/ehp.7234

Nakamura, Y.K., N. Flintoff-Dye and S.T. Omaye, 2008. Conjugated linoleic acid modulation of risk factors associated with Atherosclerosis. Nutr. Metab., 5: 22-22. DOI: 10.1186/1743-7075-5-22

Niki, E., 2004. Antioxidants and atherosclerosis. Biochem. Soc. Transact., 32: 156-159.

NRC, 2011. Guide for the Care and use of Laboratory Animals. 8th Edn., National Academic Press, Washington DC., USA., ISBN: 0309154006, pp: 220. 
Parthasarthy, S., J. Barnett, L.G. Fong, 1990. Highdensity lipoprotein inhibits the oxidative modification of low-density lipoprotein. Biochim. Biophys. Acta Lipids Lipid Metab., 1044: 275-283. DOI: 10.1016/0005-2760 (90)90314-N

Pope, C.N., 1999. Organophosphorus pesticides: Do they all have the same mechanism of toxicity? J. Toxicol. Environ. Health Part B: Critical Rev., 2: 161-181. DOI: 10.1080/109374099281205

Quistad, G.B., S.E. Sparks and J.E. Casida, 2001. Fatty acid amide hydrolase inhibition by neurotoxic organophosphorus pesticides. Toxicol. Applied Pharmacol., 173: 48-55. $\quad$ DOI: 10.1006/taap.2001.9175

Reaven, P.D., A. Khouw, W.F. Beltz, S. Parthasarathy and J.L. Witztum, 1993. Effect of dietary antioxidant combinations in humans. Protection of LDL by vitamin $\mathrm{E}$ but not by beta-carotene. Arterioscl. Thromb., 13: 590-600. PMID: 8466894

Rice, P.J., P.J. Rice, E.L. Arthur and A.C. Barefoot, 2007. Advances in pesticide environmental fate and exposure assessments. J. Agric. Food Chem., 55: 5367-5376. PMID: 17552539

Shakoori, A.R., S.S. Ali and N.A. Saleem, 1988. Effects of six months' feeding of cypermethrin on the blood and liver of albino rats. J. Biochem. Toxicol., 3: 59-72. PMID: 2466999

Shih, D.M., L. Gu, Y. Xia, M. Navab and W. Li et al., 1998. Mice lacking serum paraoxonase are susceptible to organophosphate toxicity and atherosclerosis. Nature, 394: 284-287.

Shittu, M., J.O. Ayo, S.F. Ambali, M.U. Kawu and S.O. Salami, 2012b. Vitamin E mitigates chronic chlorpyrifos-induced oxidative changes in the testes and pituitary glands in waster rats. Am. J. Applied Sci., 9: 75-82. DOI: 10.3844/ajassp.2012.75.82

Shittu, M., J.O. Ayo, S.F. Ambali, M.Y. Fatihu and B.I. Onyeanusi et al., 2012a. Chronic chlorpyrifosinduced oxidative changes in the testes and pituitary gland of Wistar rats: Ameliorative effects of vitamin C. Pestic. Biochem. Physiol., 102: 7985. DOI: $10.1016 /$ j.pestbp.2011.10.014

Slotkin, T.A., 2004a. Cholinergic systems in brain development and disruption by neurotoxicants: Nicotine, environmental tobacco smoke, organophosphates. Toxicol. Applied Pharmacol., 198: 132-151. DOI: 10.1016/j.taap.2003.06.001

Slotkin, T.A., 2004b. Guidelines for developmental neurotoxicity and their impact on organophosphate pesticides: A personal view from an academic perspective. NeuroToxicology, 25: 631-640. DOI: 10.1016/S0161-813X(03)00050-0
Sozmen, E.Y., B. Mackness, B. Sozmen, P. Durrington and F.K. Girgin et al., 2002. Effect of organophosphate intoxication on human serum paraoxonase. Hum. Exp. Toxicol., 21: 247-252. DOI: 10.1191/0960327102ht244oa

Steinberg, D., S. Parthasarthy, T.E. Carew, J.C. Khoo and J.L. Witztum, 1989. Beyond cholesterol. Modifications of low-density lipoprotein that increase its atherogenicity. N. Engl. J. Med., 320: 915-924. PMID: 2648148

Stojevic, Z., N. Filipovic, P. Bozic, Z. Tucek and J. David, 2008. The metabolic profile of Simmental service bulls. Vet. Arhiv., 78: 123-130.

Tappel, A.L., 1973. Lipid peroxidation damage to cell components. Fed. Proc., 32: 1870-1874. PMID: 4352451

Teissedre, P.L., E.N. Frankel, A.L. Waterhouse, H. Peleg and J.B. German, 1996. Inhibition of in vitro human LDL oxidation by phenolic antioxidants from grapes and wines. J. Sci. Food Agric., 70: 55-61.

Tietz, N.W., 1987. Fundamentals of Clinical Chemistry. 3rd Edn., Saunders, Philadelphia, ISBN: 0721688624, pp: 1010.

Tomas, M., G. Latorre, M. Senti and J. Marrugata, 2004. The antioxidant function of high density lipoproteins: A new paradigm in atherosclerosis. Rev. Esp. Cardiol., 57: 557-569. PMID: 15225502

Tripathi, S. and A.K. Srivastav, 2010. Liver profile of rats after long-term ingestion of different doses of chlorpyrifos. Pestic. Biochem. Physiol., 97: 60-65. DOI: 10.1016/j.pestbp.2009.12.005

Tuzmen, M.N., N. Candan and E. Kaya, 2007. The evaluation of altered antioxidative defense mechanism and acetylcholinesterase activity in rat brain exposed to chlorpyrifos, deltamethrin and their combination. Toxicol. Mech. Meth., 17: 535540. DOI: 10.1080/15376510701380463

Wen, Y., S. Killalea, P. Mcgettigan and J. Feely, 1996. Lipid peroxidation and antioxidant vitamins $\mathrm{C}$ and E in hypertensive patients. Ir. J. Med. Sci., 165: 210-212. PMID: 8824028 